\title{
Percepção da autoeficácia computacional docente dos professores da educação básica
}

\author{
Elis Renata de Britto SANTOS ${ }^{1}$ \\ Magda PISCHETOLA ${ }^{2}$
}

\section{Resumo}

Este estudo propõe um olhar diferenciado para a inserção das tecnologias digitais no campo educacional, afastando-se da perspectiva técnica e aproximando-se da percepção de artefatos culturais imersos nos hábitos, nos costumes e nas crenças dos professores. As crenças pedagógicas funcionam como filtros dos pensamentos e ações dos professores, portanto esta investigação visa analisar a percepção das crenças de autoeficácia que os professores possuem para lecionar usando as tecnologias digitais. A pesquisa qualitativa foi desenvolvida em oito escolas municipais do Rio de Janeiro, entrevistando 64 professores, durante o período de 2014 a 2019. Os resultados demonstraram que a maioria dos docentes (63) utilizaram as tecnologias no âmbito pessoal, mas, ao verificar o uso delas no ambiente escolar, esse grupo diminuiu para 47. E apenas 17 desses profissionais conseguiram modificar suas práticas pedagógicas usando as TICs. Conclui-se que a autoeficácia computacional docente não representa uma confiança contínua, pois é influenciada por vários elementos e está em constante transformação.

Palavras-chave: Crenças de autoeficácia computacional docente. Professor. Prática pedagógica. Tecnologia digital.

\footnotetext{
${ }^{1}$ Doutoranda em Ciências Humanas e Educação pela Pontifícia Universidade Católica do Rio de Janeiro (PUC-Rio). Integrante do Grupo de Pesquisa Desenvolvimento Humano e Educação (GRUDHE/PUC-Rio). ORCID. https://orcid.org/0000-0001-9862-9832 E-mail. elisbritto26@gmail.com

${ }^{2}$ Pós-doutoranda na IT-University of Copenhagen (ITU), Department of Computer Science. Professora colaboradora do quadro complementar do Programa de Pós-Graduação em Educação, na área de mídias e tecnologias em educação, da Pontifícia Universidade Católica do Rio de Janeiro (PUC-Rio). ORCID. https://orcid.org/0000-0001-6697-2118 E-mail. $\underline{\text { magd@itu.dk }}$
} 


\title{
Perception of teacher computational self-efficacy of basic education teachers
}

\author{
Elis Renata de Britto SANTOS \\ Magda PISCHETOLA
}

\begin{abstract}
The study proposes a different look at the insertion of digital technologies in the educational field, moving away from the technical perspective and approaching the perception of cultural artifacts immersed in the habits, customs and beliefs of teachers. Pedagogical beliefs work as filters of teachers' thoughts and actions, so this investigation aims to analyze the perception of self-efficacy beliefs that teachers have to teach using digital technologies. The qualitative research was carried out in 8 municipal schools in Rio de Janeiro, interviewing 64 teachers, during the period 2014-2019. The results showed that most teachers (63) used technologies in a personal scope, but when checking the school environment, this group decreased to 47 . And only 17 of these managed to modify their pedagogical practices using ICT. It is concluded that the teaching computational selfefficacy does not represent a continuous trust, as it is influenced by several elements and is in constant transformation.
\end{abstract}

Keywords: Teacher computational self-efficacy beliefs. Teacher. Pedagogical practice. Digital technology. 


\title{
Percepción de la autoeficacia computacional docente de los docentes de educación básica
}

\author{
Elis Renata de Britto SANTOS \\ Magda PISCHETOLA
}

\begin{abstract}
Resumen
El estudio propone una mirada diferente a la inserción de las tecnologías digitales en el campo educativo, alejándose de la perspectiva técnica y acercándose a la percepción de los artefactos culturales inmersos en los hábitos, costumbres y creencias de los docentes. Las creencias pedagógicas funcionan como filtros de los pensamientos y acciones de los docentes, por lo que esta investigación tiene como objetivo analizar la percepción de las creencias de autoeficacia que tienen los docentes para enseñar utilizando tecnologías digitales. La investigación cualitativa se realizó en 8 escuelas municipales de Río de Janeiro, entrevistando a 64 docentes, durante el período 2014-2019. Los resultados mostraron que la mayoría de los docentes (63) utilizaron tecnologías en un ámbito personal, pero al verificar el entorno escolar, este grupo disminuyó a 47. Y solo 17 de ellos lograron modificar sus prácticas pedagógicas utilizando las TIC. Se concluye que la autoeficacia computacional del docente no representa una confianza continua, ya que está influenciada por varios elementos y está en constante transformación.
\end{abstract}

Palabras clave: Creencias de autoeficacia computacional del maestro. Profesor. Práctica pedagógica. Tecnología digital. 


\section{Introdução}

Atualmente, existe uma grande inquietude quanto à necessidade de reinventar a escola, como afirma Candau (2020), já que a perspectiva tradicional do trabalho do docente como detentor do saber e os alunos como seus espectadores não atende mais as necessidades da sociedade atual. Entretanto reinventar não significa descartar o que existe e construir novos significados, mas propor um diálogo entre o que já foi elaborado e as novas questões que surgem nesse novo contexto educacional.

Esse novo cenário educacional é permeado por variadas questões, incluindo a presença das tecnologias de informação e comunicação (TICs), que, inicialmente, pautava-se no discurso de que iriam proporcionar maior acesso à informação e melhoria da educação (KENSKI, 2012; PISCHETOLA et al., 2019). Todavia é notório que a educação, mesmo diante de todos esses novos questionamentos, ainda permanece formal, previsível, repetitiva, burocrática e pouco atraente. Portanto, como defende Moran (2013), não são os recursos tecnológicos que definem a escola e a aprendizagem, mas sim as pessoas e as suas interações.

Diante dessa conjuntura, percebe-se que as tecnologias digitais devem ser interpretadas como artefatos culturais porque são elementos constituintes da cultura, pois promoveram modificações no âmbito pessoal, social, profissional, comunicacional, entre outros. Assim, a tecnologia é constituinte da cultura e não coadjuvante desta, por isso não se devem observar apenas seus efeitos e possibilidades, e sim a sua potencialidade de influenciar novas formas de pensar e desenvolver atividades (BRITTO, 2009).

A inserção das tecnologias digitais na escola é vista hoje como algo inevitável, e por isso aparece nos discursos dos professores, da direção e até na legislação como a tábua de salvação da educação. Contudo diversas pesquisas apontam que as tecnologias, por si sós, não trazem melhorias qualitativas para as aulas nem para o processo de ensino-aprendizagem, indicando que essa é uma visão de senso comum que precisa ser desmitificada no interior desse processo (CANDAU, 2018; NAUMANN; PISCHETOLA, 2017; HEINSFELD, 2018).

Para Pischetola (2016; 2018b), a educação precisa reconhecer que as TICs são mais do que simples ferramentas que proporcionam um suporte ao trabalho docente. Na verdade, elas representam artefatos culturais porque modificam as ações, os pensamentos, as crenças e os hábitos do indivíduo. Sem essa visão cultural das tecnologias, tem-se a impressão de que a educação, quanto às práticas pedagógicas, está estruturada, encaixada e segue um rígido padrão, logo a educação não se renova, e as normas e técnicas utilizadas permanecem as mesmas sem nenhuma inovação pedagógica. 
Este estudo buscou desenvolver uma investigação cujo foco é a prática pedagógica do docente e a sua correlação com as TICs, pois se acredita nas infinitas interações e aprendizagens que podem ser desenvolvidas com a relação triádica entre professor-tecnologia-aluno. Acredita-se que um docente, ao entrar em sala, não carrega consigo apenas os conteúdos da sua disciplina, mas uma série de crenças e valores que julga importante para o seu ofício.

Nesse sentido, as relações entre as crenças e as práticas dos professores podem ajudar a esclarecer como esses profissionais decidem integrar as tecnologias ao ensino e produzir efeitos positivos e duradouros no processo de ensino-aprendizagem, beneficiando tanto os alunos quanto os professores (SADALLA; SARETTA; ESCHER, 2002; CHEN, 2008; BUSTOS NAVARRETE, 2012; ZAMBON et al., 2012).

Portanto o presente estudo procurou não se ater somente à observação da prática docente, mas sim compreender o que existe por trás dela, o que a impulsiona e a motiva. Por que escolher aquela técnica? Quais são as convicções daquele professor para ensinar aquele conteúdo daquela forma? O caminho desenvolvido na pesquisa foi analisar os componentes psicológicos que podem interferir na confiança dos professores quanto ao emprego das tecnologias na sala de aula em relação às crenças pedagógicas.

As crenças pedagógicas dos docentes estão ligadas ao planejamento das atividades educativas quanto ao emprego das tecnologias, uma vez que tais crenças funcionam como um guia, determinando as prioridades na seleção dos métodos e dos conhecimentos necessários para a prática docente com as TICs (CHEN, 2008; BUSTOS NAVARRETE, 2012; ZAMBON et al., 2012).

Dessa forma, as crenças pedagógicas influenciam as percepções e os julgamentos dos professores sobre as informações, as regras, os conteúdos, os valores que devem existir em uma sala. Elas impulsionam a conduta da aula e as práticas pedagógicas para lidar com diferentes situações do contexto e até as próprias características pessoais dos docentes. Como as crenças pedagógicas expressam um campo científico muito amplo, este estudo desenvolveu sua investigação a partir de um recorte mais específico, pautado nos ensinamentos do psicólogo Albert Bandura, como as crenças de autoeficácia.

Portanto este estudo tem o propósito de compreender a percepção dos professores quanto a sua autoeficácia computacional docente, isto é, como essa crença interfere na confiança do professor para ensinar usando as TICs, uma vez que tal crença funciona como uma espécie de filtro para os docentes selecionarem conteúdos, técnicas, princípios e valores para lecionarem, ou seja, representam o fio condutor entre o pensamento e a prática pedagógica. 


\section{O papel das crenças na didática docente}

Todos os seres humanos têm diferentes tipos de crenças que diariamente podem se fortalecer ou enfraquecer de acordo com as influências diretas ou indiretas a que estão submetidos, por exemplo, suas vivências e seu contexto social. Nesse sentido, é através das crenças que os indivíduos pensam, agem de forma diferenciada, de acordo com cada momento. Por meio delas, o indivíduo entende a si mesmo, os outros e convive em sociedade.

Este estudo compreende que as crenças representam um conjunto de ideias e proposições estruturadas em um sistema, ligadas às experiências de vida que um indivíduo possui. Ele tem essas crenças como verdades, sendo estas conscientes ou não (BORG, 2001; BARCELOS, 2007). As crenças funcionam como um mediador entre o pensamento (o que o sujeito acredita) e a ação (o comportamento pautado nessas proposições), logo regulam a conduta do indivíduo.

No campo educacional, é primordial o estudo das crenças, uma vez que estas têm um caráter ativo e estão em constante transformação porque são influenciadas pelas diferentes histórias de vida e experiências do sujeito, pelas suas distintas aprendizagens e pelos variados aspectos socioculturais a que ele é submetido (OLIVEIRA, 2001). Na educação, as crenças interferem diretamente na organização do conhecimento, na seleção de informações importantes para o processo de ensinoaprendizagem, na prática pedagógica, entre outros elementos (PAIVA; DEL PRETTE, 2009).

Como o professor é a figura central do processo de mediação pedagógica entre o conhecimento e o aluno, este estudo procurou compreender como esse profissional articula seus pensamentos, suas decisões e seus comportamentos intimamente ligados às suas crenças pedagógicas tão primordiais para o desenvolvimento de sua prática docente e dos alunos.

As crenças atuam como um filtro ou uma lente através dos quais os docentes processam informações, valores, perspectivas e expectativas em relação às suas ações didáticas e à aprendizagem dos alunos (NAVARRO, 2002). A rotina docente, conforme Perrenoud (2001), baseia-se no paradoxo de agir na urgência e decidir na incerteza, portanto esses profissionais necessitam constantemente reorganizar o seu pensamento e suas ações consultando suas crenças. É necessário enfatizar que os desafios do cotidiano do trabalho docente impulsionam os professores a reavaliar sempre suas crenças e decisões (EICKELMANN; VENNEMANN, 2017).

Segundo Nespor (1987), as mudanças nas crenças dos professores só são possíveis quando estes se tornam reflexivos e autoconscientes delas, pois a consciência permite a postura reflexiva, sendo 
essencial no enfrentamento da crise da epistemologia da prática profissional. Essa reflexão pedagógica é fundamental porque permite a compreensão não só dos objetivos, dos conteúdos e das metodologias utilizadas pelo professor, mas também dos pensamentos, das concepções, das teorias e das próprias crenças pedagógicas que impulsionam a ação docente (SCHÖN, 2000; HARTMAN, 2015; NAVARRO, 2007; EICKELMANN; VENNEMANN, 2017; RAMALHO; NÚÑ̃ZZ, 2019).

Devido à amplitude do constructo crenças pedagógicas, este estudo compreende a relação entre esse elemento subjetivo e o uso das TICs a partir da crença de autoeficácia, definida por Bandura (1997) como a confiança do indivíduo em organizar e executar as tarefas.

\section{Autoeficácia computacional docente}

A autoeficácia é um constructo defendido pelo psicólogo Albert Bandura nos seus variados estudos como um elemento central da Teoria Social Cognitiva (TSC), cujo foco é a explicação dos princípios do funcionamento humano pautados na perspectiva da agência humana (BANDURA, 2018; AZZI; POLYDORO, 2006; AZZI, 2014).

A TSC se desenvolve a partir da concepção da agência humana, isso porque as pessoas estabelecem metas, realizam compromissos sociais, desenvolvem planos de ação, assim, são capazes de moldar os cursos de suas vidas no presente e até no futuro (BANDURA, 2018). Isso posto, "ser agente significa influenciar o próprio funcionamento e as circunstâncias de vida de modo intencional" (BANDURA, 2008, p. 15).

Dessa forma, as pessoas são agentes de suas existências e não apenas receptores das situações, já que podem influenciar, de modo proposital, o próprio funcionamento. Logo, na visão sociocognitiva, as pessoas são produtos e produtoras do meio. Bandura (2001), autor dessa teoria, ainda esclarece que o indivíduo não nasce agente, mas torna-se um a partir da construção social fruto das suas interações com o ambiente, produzindo diferentes comportamentos (BANDURA, 2001; AZZI, 2014).

Um mecanismo muito importante para a agência humana é a crença de autoeficácia porque simboliza a força que um indivíduo possui para realizar uma atividade e atingir seus objetivos. Essa crença funciona como um regulador do comportamento humano a partir do funcionamento dos aspectos cognitivos, motivacionais, afetivos e decisórios, pois influencia o modo de pensar e agir dos indivíduos pautado pelos valores autoincentivadores ou autoenfraquecedores que os motivam ou não diante das dificuldades (BANDURA, 2017). 
A definição atual de crença de autoeficácia foi aprimorada com o desenvolvimento de várias pesquisas buscando compreender como as pessoas sentem, pensam, motivam-se e se comportam, portanto variável chave para agência humana. Para Bandura (1997, p. 3), autoeficácia corresponde “às crenças do indivíduo em sua capacidade em organizar e executar cursos de ação requeridos para produzir certas realizações".

Nesse sentido, a autoeficácia é vista como um julgamento pessoal da competência que um indivíduo tem para realizar uma tarefa. Portanto essa crença o auxilia na escolha do que fazer, ou melhor, a seleção das tarefas é influenciada pelo sentimento de confiança do indivíduo em realizálas, logo quanto maior o senso de autoeficácia, maior a persistência diante dos desafios (AZZI; VIEIRA, 2014).

Assim, as crenças da autoeficácia são construídas ao longo da vida, a partir das influências dos aspectos pessoais, comportamentais e ambientais que constituem a base para a motivação humana, mediando também suas ações. Entretanto apenas a existência da crença de autoeficácia não garante o sucesso da realização da ação, pois também é necessária a presença do conhecimento e da habilidade, isto é, não basta ter confiança, acreditar que é capaz. Se o indivíduo não possui conhecimento e habilidade para realizar uma ação, mesmo com elevada autoeficácia, ele terá dificuldade em executar tal tarefa (CORRY; STELLA, 2018).

De um modo mais simples, pode-se dizer que a autoeficácia é o julgamento do que pode ser feito com as habilidades que o indivíduo possui, portanto conhecimento e habilidade são de extrema importância para essa crença, já que não adianta ter confiança sem conhecimentos e habilidades, da mesma forma que conhecer um determinado assunto e ser hábil sem a confiança não é garantia de sucesso (BANDURA, 1997; CORRY; STELLA, 2018).

Desse modo, autoeficácia é a mediadora do pensamento e da ação por meio da habilidade do indivíduo e da capacidade de usar essas habilidades, isto é, representa o julgamento da própria confiança em executar ações, atingindo certo grau de sucesso. Se as pessoas não acreditam que suas ações produzirão resultados positivos, dificilmente ficam motivadas para agir e persistir naquele desafio. Dessa forma, as pessoas precisam associar conhecimento, habilidade e confiança (crença da autoeficácia) para garantir que o desempenho seja atingido (BANDURA, 1986; 1989; ERTMER; OTTENBREIT-LEFTWICH, 2010).

A relação da crença de autoeficácia com a prática docente suscita o seu papel intercessor, isto é, essa crença torna-se a mediadora entre o conhecimento do docente e a sua própria prática pedagógica (AZZI; POLYDORO; BZUNECK, 2006). Como ensinar é um procedimento complexo, que envolve diversas interações sociais com diferentes sujeitos, e o professor é um importante 
personagem nessas interações, torna-se fundamental compreender a sua motivação e o seu comportamento, portanto é preciso conhecer suas crenças sobre sua confiança na capacidade de ensinar, isto é, investigar qual é a sua autoeficácia docente.

Os professores possuem diferentes tipos de crenças, entretanto o foco deste estudo está voltado para a observação das crenças desses profissionais na sua capacidade para ensinar e promover a aprendizagem (autoeficácia docente). Tschannen-Moran e Woolfolk Hoy (2001) e Navarro (2007) sinalizam que as crenças dos professores não são unitárias, apresentando dois direcionamentos: as crenças relativas às tarefas de ensino, envolvendo a eficácia de ensino, e as crenças sobre a competência para ensinar, isto é, sobre a eficácia pessoal do professor (autoeficácia docente).

As crenças de autoeficácia docente intervêm no modo como o professor nota, deduz, compreende, aprende e realiza as suas atividades. Em síntese, essas crenças correspondem à capacidade do docente em ensinar e contribuir para a aprendizagem dos alunos (KAGAN, 1992; PAJARES, 1992; 1996). Portanto elas refletem no comportamento do professor (prática docente), isto é, influenciam o modo como esses profissionais se sentem, pensam, escolhem ou não as atividades, persistem diante dos obstáculos, assim como intervêm no grau de motivação (AZZI; POLYDORO; BZUNECK, 2006; AZZI et al., 2014).

Ao realizar o julgamento sobre sua própria eficácia pessoal, o docente considera o que está sendo exigido dele naquela situação de ensino juntamente com as demandas do contexto no qual exerce sua prática pedagógica. Assim, ele interpreta a relação entre a dificuldade da atividade e a habilidade e capacidade necessárias para obter sucesso na realização da tarefa de ensinar (AZZI; VIEIRA, 2014). Portanto é extremamente relevante ressaltar que a percepção de autoeficácia é mutável, já que depende das variáveis pessoais e contextuais. Nesse sentido, um professor pode se perceber altamente eficaz para conversar sobre um determinado assunto, mas a sua confiança para ensinar sobre ele é menor (AZZI; POLYDORO; BZUNECK, 2006).

De acordo com algumas pesquisas sobre a autoeficácia docente, aqueles professores com crenças mais consolidadas conseguem desenvolver novas estratégias para o ensino, enfrentam melhor as situações difíceis, apresentam mais facilidade na adequação às mudanças, aumentam seus esforços e persistências em atividades mais complexas, sentem-se mais propícios a adotar práticas inovadoras de ensino e posicionam-se como mais democráticos na sala de aula (NAVARRO, 2002, 2007; AZZI; POLYDORO; BZUNECK, 2006; GOYA et al., 2008).

Em suma, a crença de autoeficácia docente representa um guia entre o ensino e a comunicação estabelecida entre professores e alunos, influenciando as respectivas motivações e o rendimento 
destes últimos. Nesse sentido, os professores mais autoeficazes, além de se sentirem mais confiantes para ensinar, também são aqueles que possuem maiores expectativas em relação à sua aprendizagem e, portanto, mostram-se mais abertos para possíveis inovações no processo de ensino-aprendizagem (NAVARRO, 2007).

Observando a escola nos dias de hoje, percebe-se que a inserção das tecnologias na educação não é algo recente, porém está se tornando mais intensa e abrangente. Diante desse desafio, este estudo teve o propósito de observar a relação intrínseca entre a autoeficácia docente e as tecnologias de informação e comunicação, uma vez que alguns professores têm facilidade e outros apresentam dificuldades quanto ao uso de tais recursos (CANDAU; CRUZ; FERNANDES, 2020).

A literatura afirma que a tecnologia, por si só, não consegue promover mudanças na educação, necessitando da figura do professor, que deve assumir a responsabilidade da mediação pedagógica entre o conhecimento, o aluno e a tecnologia. Nesse sentido, incorporar as tecnologias digitais na prática docente consiste em mudar suas crenças tradicionais, compreendendo que o aluno é o principal agente do seu processo de aprendizagem (EICKELMANN; VENNEMANN, 2017; TONDEUR $e t$ al., 2017).

Como as crenças guiam a conduta e o comportamento dos professores, torna-se fundamental o conhecimento da sua relação com as tecnologias digitais, pois é por meio delas que o docente se julga capaz de usar os aparatos tecnológicos, apropria-se das inovações e desenvolve novas metodologias para o processo de ensino-aprendizagem. Um aspecto relevante para a mudança ou o fortalecimento das crenças de autoeficácia docente é a reflexão crítica sobre a prática pedagógica (ERTMER; OTTENBREIT-LEFTWICH; TONDEUR, 2014; HATLEVIK; HATLEVIK, 2018; RAMALHO; NÚÑEZ, 2019; NELSON; HAWK, 2020).

Dessa forma, o posicionamento positivo dos docentes diante das mudanças e da inovação pode representar uma postura confiante em relação à integração das TICs ao ensino, logo existe uma correlação entre a autoeficácia docente e o uso das tecnologias digitais, retratando a autoeficácia computacional docente (ERTMER; OTTENBREIT-LEFTWICH; TONDEUR, 2014; ALVARENGA, 2011).

Para Alvarenga e Azzi (2010, p. 68), a autoeficácia computacional docente "refere-se à crença do professor em sua capacidade para utilizar tecnologias computacionais ou de informação e comunicação (como computador, softwares e internet) no processo de ensino e aprendizagem dos seus alunos ou integrá-las ao ensino".

O professor, ao se deparar com um recurso pedagógico ou tecnológico, realiza um julgamento se aquela ferramenta pode ser relevante para o seu trabalho, para auxiliar os alunos no estudo e para 
desenvolver uma aprendizagem mais eficaz. Essa análise é pautada pelas crenças e pelos valores prévios que cada professor possui, e isso afeta o processo de implementação do novo recurso ao cotidiano do professor, do aluno e da escola (ERTMER; OTTENBREIT-LEFTWICH, 2010; TONDEUR et al., 2017).

A crença da autoeficácia computacional docente é também uma variável importante para a compreensão da motivação dos docentes quanto ao uso das TICs, já que influencia os objetivos que se pretende alcançar, o esforço empregado nas atividades, a persistência nas tarefas mais difíceis e o enfrentamento do fracasso. Assim, professores com alto nível de autoeficácia para ensinar com tecnologias tendem a ser mais motivados, despendem mais esforços e persistem em tarefas que envolvem o uso de tecnologias muito mais do que professores com níveis baixos da crença da autoeficácia computacional docente. A confiança do professor na sua capacidade em usar as tecnologias digitais para facilitar a aprendizagem do aluno aumenta a probabilidade de que esse profissional as utilize em suas aulas (HATLEVIK; HATLEVIK, 2018; RAMALHO; NÚÑEZ, 2019; NELSON; HAWK, 2020).

\section{A pesquisa empírica}

A pesquisa qualitativa ${ }^{3}$ foi desenvolvida entre os anos de 2014 e 2019, em oito escolas públicas municipais do Rio de Janeiro, que atendiam o segundo segmento do ensino fundamental. A investigação objetivava compreender como os professores da educação básica se apropriavam das tecnologias digitais nas suas práticas pedagógicas a partir da crença de autoeficácia computacional docente.

As escolas que participaram da pesquisa localizavam-se em diferentes bairros do município do Rio de Janeiro, e tal condição expressava diferentes características socioculturais, assim como os diversos participantes da pesquisa (professores) também circulavam por diferentes espaços urbanos, portanto apresentavam distintas visões de mundo. As instituições de ensino foram indicadas pela Secretaria Municipal de Educação (SME/RJ) para participar da pesquisa, pois, segundo esse órgão,

\footnotetext{
${ }^{3}$ Este estudo esteve inserido em um projeto institucional de um grupo de pesquisa de uma instituição privada de Ensino Superior do estado do Rio de Janeiro.
} 
desenvolviam práticas inovadoras com as tecnologias digitais. E os sujeitos da pesquisa foram 8 professores de cada unidade escolar, ${ }^{4}$ totalizando 64 participantes.

Para garantir a ética da pesquisa, tanto as escolas quanto os professores foram identificados na pesquisa por um código alfanumérico, registrados pelo intervalo de 01 a 08 e pelas letras "e" e "p", indicativas das palavras "escola" e "professor", respectivamente. O instrumento metodológico utilizado foi um roteiro de entrevista semiestruturada com nove perguntas que poderiam se desdobrar em outros questionamentos durante a interação entrevistado e pesquisador, visando atender melhor ao objetivo da pesquisa (PISCHETOLA et al., 2019).

A análise dos dados foi feita por meio do software Atlas Ti versão 8.0, pautada pela abordagem da análise de conteúdo (BARDIN, 2011), pela Teoria Fundamentada em Dados (GLASER; STRAUSS, 1967) e pelo aporte teórico defendido pelo psicólogo Albert Bandura, especificamente a crença de autoeficácia (BANDURA, 1977). Em um primeiro momento, foi desenvolvida a codificação, transformando os dados brutos em dados organizados através das unidades de registro temáticas (autoeficácia computacional e autoeficácia computacional docente), baseadas na literatura adotada neste estudo. Num segundo momento, ocorreu a categorização, em que os dados foram separados a partir das semelhanças ou diferenças das informações, surgindo duas categorias (alta e baixa) representadas pelas particularidades da realidade vivenciada por cada participante.

\section{Resultados}

Por meio da análise dos dados obtidos com as entrevistas, foi possível perceber uma variação no nível da percepção da confiança dos docentes quanto ao uso das tecnologias (crença) na sua prática pedagógica em benefício da aprendizagem dos discentes. Como essas crenças não foram expostas de maneira clara, pois nem sempre há uma consciência delas, alguns professores estão alocados em dois ou mais níveis ao mesmo tempo (NAVARRO, 2007).

De acordo com a análise das falas dos docentes sobre o uso das tecnologias no seu cotidiano pessoal e profissional (prática pedagógica), foram encontrados cinco níveis de percepção da confiança diante dos artefatos tecnológicos. Esses níveis foram identificados por letras (A, B, C, D e E), expressando desde aqueles professores que têm dificuldade para utilizar a tecnologia ou fazem uso

\footnotetext{
${ }^{4} \mathrm{Na}$ escola 07 , foram entrevistados somente 7 professores, devido à disponibilidade dos participantes. Entretanto, objetivando alcançar o quantitativo de docentes estipulado no projeto de pesquisa entregue à SME-RJ, na escola 08, foram entrevistados 9 professores, totalizando 64 entrevistas do projeto.
} 
apenas no contexto pessoal (autoeficácia computacional - AC) até aqueles que conseguiram inovar suas práticas pedagógicas (autoeficácia computacional docente - ACD). A crença dos professores também variou entre elevada e baixa confiança para utilizar as tecnologias digitais (SANTOS; ALBUQUERQUE, 2018; RIEDNER, 2018). O Quadro 1 apresenta os cinco níveis de percepção da confiança dos professores no uso das tecnologias digitais no contexto pessoal e profissional.

Quadro 1 - Variação no nível da percepção da confiança do docente quanto ao uso das tecnologias

\begin{tabular}{|c|c|}
\hline NÍVEIS & DESCRIÇÃo \\
\hline A & Baixa Autoeficácia Computacional (AC) \\
\hline B & Elevada Autoeficácia Computacional (AC) \\
\hline C & Baixa Autoeficácia Computacional Docente (ACD) \\
\hline D & Elevada Autoeficácia Computacional Docente (ACD) \\
\hline E & Elevada ACD + Inovação pedagógica \\
\hline
\end{tabular}

Fonte: Elaborado pelas autoras.

No campo teórico, existe uma diferença entre os conceitos de autoeficácia computacional (AC) e autoeficácia computacional docente (ACD). O primeiro consiste no uso da tecnologia no contexto pessoal, como enviar e-mails, preencher planilhas, elaborar documentos e apresentações, entre outras tarefas. Já o segundo corresponde à capacidade dos professores quanto ao uso significativo dos artefatos tecnológicos para a aprendizagem dos alunos (SANTOS; ALBUQUERQUE, 2018; ALVARENGA; AZZI, 2010; COMPEAU; HIGGINS, 1995).

No Quadro 1, o primeiro nível, identificado com a letra “ $A$ ”, correspondeu aos professores que apresentaram baixa autoeficácia computacional $(A C)$, sendo incluídos nesse nível aqueles docentes que apresentavam dificuldade para usar a tecnologia e quando o faziam, era de forma bastante restrita. O segundo nível, identificado com a letra “ $B$ ”, reuniu aqueles professores que faziam uso das tecnologias no seu contexto pessoal por meio de editor de textos, planilhas, banco de dados e usavam a internet para fins pessoais ou didáticos, como buscar materiais para preparar suas aulas. E, ao fazerem o uso dos artefatos digitais na sala de aula, apresentavam práticas pedagógicas tradicionais, como aulas expositivas com slides, exibição de filmes e outros recursos, portanto foram aqueles docentes considerados com elevada autoeficácia computacional (AC).

O terceiro nível, nomeado como " $C$ ", foi classificado como de baixa autoeficácia computacional docente (ACD), correspondendo aos professores que apresentaram, no seu discurso, uma baixa percepção da sua confiança para o uso das tecnologias digitais na sala de aula. Esses docentes não acreditavam na sua capacidade para usar os recursos tecnológicos e promover a 
participação ativa dos alunos colaborando com uma aprendizagem mais significativa. O quarto nível, identificado como “ $D$ ”, reuniu professores com uma elevada percepção da sua confiança quanto ao uso das TICs na sala de aula, portanto sentiam-se com elevada autoeficácia computacional docente $(A C D)$. E o último nível, denominado " $E$ ”, foi criado para distinguir os professores que apenas se sentiam confiantes para usar as TICs daqueles que, além da confiança, conseguiram inovar suas práticas pedagógicas. Portanto o último nível é uma subcategoria do nível anterior, devido à transposição da elevada autoeficácia computacional docente para a prática pedagógica.

Segundo Navarro (2007), as crenças pedagógicas são fundamentais para o trabalho dos docentes porque impulsionam esses profissionais para tomar uma decisão e realizar uma determinada ação de acordo com os valores e ideais nos quais acreditam. Assim, as crenças pedagógicas fazem parte do professor, pessoal e profissionalmente. Entretanto é essencial lembrar que essas crenças são influenciadas por diversas variáveis pessoais e contextuais, tornando-se dinâmicas e oscilantes.

Analisando quantitativamente os diferentes níveis de percepção da confiança dos docentes quanto ao uso das tecnologias encontrados na pesquisa, no nível A foi registrado um total de 15 professores, representando um percentual de $23 \%$ da amostra, isto é, menos de 1/4 dos docentes expressaram dificuldades quanto ao uso das tecnologias digitais no seu cotidiano. O segundo nível, o B, totalizou 63 professores (98\%), indicando que a maior parte dos professores se enquadra nesse nível, pois consegue usar a tecnologia no seu dia a dia ou faz uso tradicional desses recursos nas salas de aula.

No terceiro nível (C), 39 professores apresentaram baixa autoeficácia computacional docente, logo $60 \%$ da amostra não se sentia apta para implementar o uso das TICs na sala de aula, de modo a promover uma aprendizagem mais colaborativa por meio da participação ativa dos alunos. Já no nível D foram encontrados 46 professores, correspondendo a $72 \%$ dos profissionais confiantes na sua capacidade de lecionar usando as TICs. E o último nível (E) registrou apenas 17 professores, indicando que apenas $27 \%$ dos docentes participantes desse estudo, além de se sentirem confiantes, conseguiram inovar suas práticas pedagógicas.

\section{Baixa autoeficácia computacional (AC) - nível A}

Spiteri e Rundgren (2020) realizaram uma revisão de literatura sobre os fatores que afetam os docentes quanto ao uso das tecnologias digitais na sua prática pedagógica. Este estudo procurou aprofundar essa análise a fim de perceber quais poderiam ser as distintas nuances refletidas na ação docente a partir de suas crenças. 
No nível A, foi obtido o índice mais alto de docentes com dificuldade nas escolas 04 e 08. Contudo esses professores apresentaram uma postura proativa demonstrada pelo interesse em ampliar o seu conhecimento sobre as tecnologias e até aprimorar suas práticas pessoais e profissionais, ou seja, pretendem usar a tecnologia na sala de aula, auxiliando os alunos na obtenção de uma aprendizagem relevante com o uso das TICs.

Nesse sentido, o estudo percebeu que existiam outras subcategorias dentro desse nível, identificadas como elementar, transição e com esforço. Na primeira subcategoria, foram encontrados cinco professores que expuseram grande dificuldade em usar as TIC no âmbito pessoal e profissional, logo foram incluídos no nível elementar, já que não vislumbravam relevância das TICs no contexto pessoal e profissional e não pretendiam modificar suas práticas pedagógicas para inseri-las. A segunda subcategoria reuniu apenas três professores, representando aqueles que estavam em estágio transitório, ora julgando as TICs importantes, ora enxergando mais os obstáculos do que as vantagens do seu uso. E a última subcategoria apresentou sete docentes que, mesmo com dificuldade, reconheciam a importância das tecnologias e concordavam que ela facilitava vários processos e, por essa razão, canalizavam esforços para ampliar o seu conhecimento e até desejavam implementar tais recursos em suas práticas pedagógicas.

A maioria dos docentes do nível A encontra-se nas subcategorias transição ou com esforço, o que indica que esses profissionais não oferecem resistência ao uso dos dispositivos digitais e ainda que estão abertos e curiosos para aprender e utilizar algo novo no ensino. Contudo a mudança só é possível a partir do momento em que os docentes enxergam as tecnologias digitais como cultura e percebem a necessidade de modificar toda a estrutura da aula, não mais as aceitando apenas como um adendo à sua prática pedagógica (PISCHETOLA, 2016; 2018b).

Conforme apontado pela literatura, as crenças de autoeficácia interferem na prática docente, na motivação e no desempenho dos alunos, logo o comportamento do professor diante das TICs também pode ser influenciado pela percepção do quanto se sente capaz de apropriar-se das inovações na sua prática pedagógica (NAVARRO, 2002; ERTMER et al., 2003; GOYA et al., 2008; AZZI et al., 2006; ALBION, 2009; ALVARENGA, 2014). Para ilustrar as características do nível A, apresentam-se a seguir algumas falas desses docentes divididos pelas duas subcategorias mais marcantes (Quadro 2). 
Quadro 2 - Trechos das falas dos docentes do nível A de acordo com as subcategorias

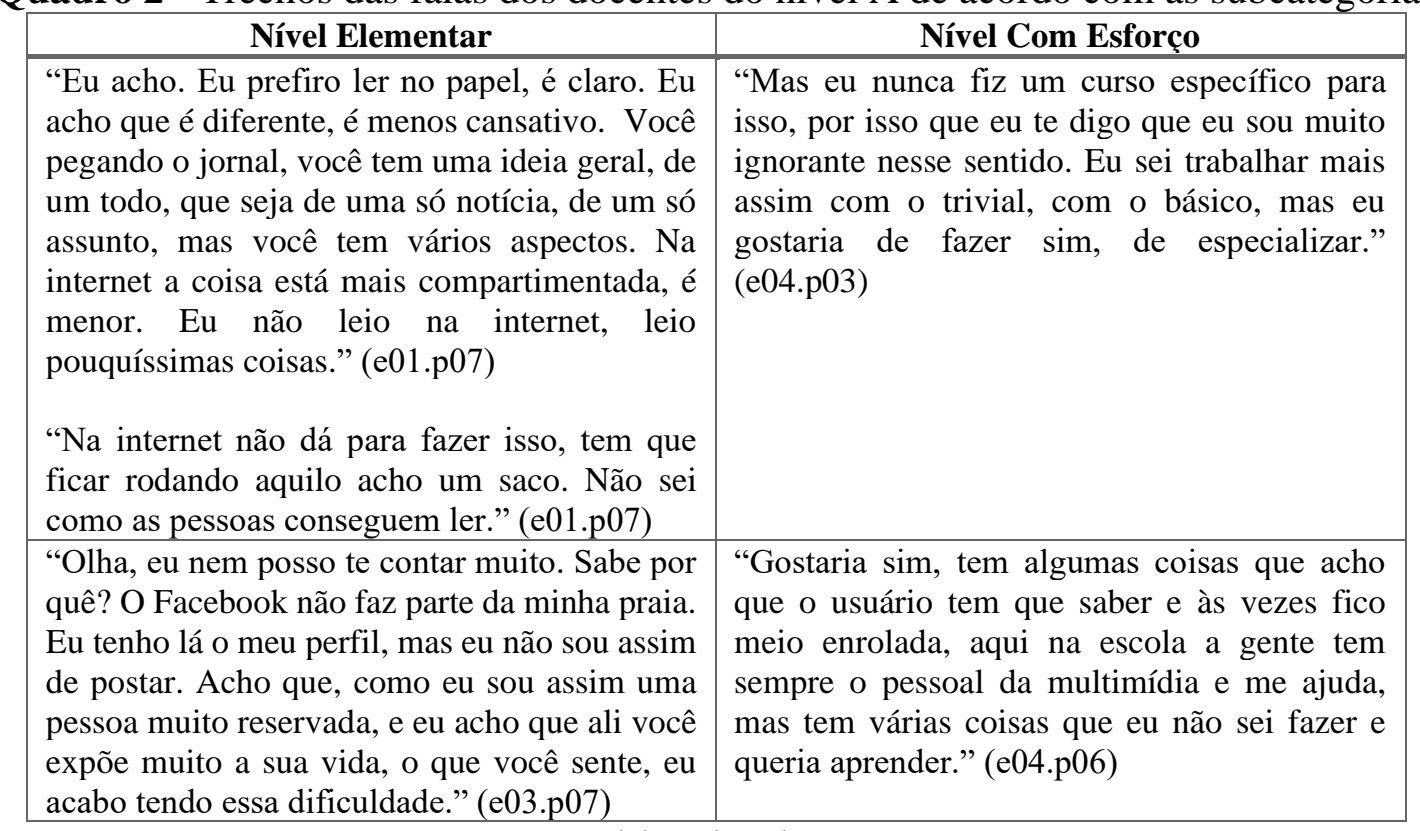

Fonte: Elaborado pelas autoras.

Os docentes da subcategoria elementar não se sentem confiantes diante das suas capacidades com as TICs e preferem não utilizar tais recursos no seu cotidiano pessoal e profissional, isto é, a falta de confiança influencia os próprios níveis de autoeficácia (PEDRO, 2011). Por outro lado, Peinado e Olmedo (2013) pontuam que a frequência do uso das TICs apresenta efeitos significativos sobre a autoeficácia computacional, pois quanto maior o uso das tecnologias, mais a confiança em sua capacidade para usar tais recursos aumenta.

Analisando os docentes da subcategoria com esforço, percebe-se que esses profissionais, ao demonstrarem uma dedicação e persistência para se apropriar das TICs no ensino, podem fortalecer suas crenças de autoeficácia computacional docente e permanecer apoderando-se dos recursos tecnológicos com o tempo e, assim, sentir-se cada vez mais eficazes. Esses resultados foram semelhantes aos sinalizados no estudo feito por Alvarenga (2014).

Destaque-se, ainda, que o número reduzido de professores no nível A ilustra que boa parte da equipe docente das escolas estudadas tem alguma familiaridade com a tecnologia, representando uma tendência dos dias atuais, seja porque se sentem "obrigados", já que a transformação da sociedade da informação é inevitável, seja para acompanhar a geração dos alunos, "nativos digitais”, como afirma Prensky (2001), cujo interesse é o computador, a internet, o celular e outros aparatos tecnológicos (ALVARENGA, 2014; PISCHETOLA, 2016; PISCHETOLA; HEINSFELD, 2018; PISCHETOLA, 2018a). 
Assim, o esperado dos professores e dos alunos após a sua familiarização com as TICs não é o domínio de símbolos, regras e habilidades técnicas, mas o desenvolvimento de práticas que permitam a construção e a manutenção das diferentes relações sociais através das tecnologias. Vários autores concordam que a inserção das TICs na educação deve ocorrer de forma crítica, reconhecendo as vantagens e desvantagens para o contexto pedagógico. Ainda é importante ressaltar que os professores têm dificuldade de integrar as TICs ao ensino devido à precariedade da sua formação profissional e, quando o fazem, limitam-se à sua forma técnica (RIEDNER; PISCHETOLA, 2016).

\section{Elevada autoeficácia computacional (AC) - nível B}

A maior parte dos professores das escolas se enquadra no nível $\mathrm{B}$, isto é, consegue usar a tecnologia no seu dia a dia, principalmente fazendo uso pessoal dela. Conforme observado nas falas dos docentes do nível B, percebe-se que os professores usam as tecnologias no contexto pessoal para distintas finalidades, principalmente procurar e desenvolver materiais para trabalhar nas suas aulas com os alunos.

No quantitativo de docentes do nível B, nota-se que todas as unidades escolares apresentaram professores com elevado nível de percepção da autoeficácia computacional (AC). Dessa forma, esses profissionais conseguem usar as tecnologias no seu cotidiano pessoal, escrevendo documentos, montando apresentações, enviando e-mails, etc. Entretanto é possível afirmar que esse quantitativo elevado pode estar sendo impulsionado pela representatividade de docentes que realizam aulas tradicionais com o uso da tecnologia.

Esse dado é bastante significativo e chama atenção para um ponto relevante encontrado nas entrevistas, que foi a resistência dos docentes quanto ao uso das TICs no ensino, o que pode ser interpretado pela ausência de apoio ou pelas críticas que esses profissionais sofrem quando usam ou pensam em usar as TICs na sala de aula, assim como pela pouca compreensão do que fazer com essas ferramentas no contexto pedagógico e pelas pequenas experiências diretas envolvendo as tecnologias digitais (ERTMER, 2005; TIRADO-MORUETA; AGUADED-GOMÉZ, 2014).

Pischetola $(2016,2018$ b) afirma que o discurso de resistência dos professores diante das TICs está ligado ao fato de que a sociedade se modernizou e a escola não, e os professores ainda estão apegados às práticas tradicionais. Contudo essa autora esclarece que, muitas vezes, os docentes encontraram-se dispostos e abertos para a novidade, mas se esquecem de que a mudança mais importante não é na burocracia e na infraestrutura, e sim na didática, no seu método de dar aula. É 
importante enfatizar que essa mudança só é exequível por meio de várias tentativas e erros, porque só assim é possível aprimorar as habilidades, aprender com as experiências e encontrar a melhor forma de trabalhar com as tecnologias digitais na educação.

Ainda foram registradas nesse nível as práticas pedagógicas tradicionais com as TICs, ressaltando-se a sua utilização como ferramenta, já que não houve mudanças nas práticas pedagógicas, ou seja, continuando o desenvolvimento de aulas expositivas com pequena ou nenhuma interação e participação dos alunos (KENSKI, 2012; MASETTO, 2013; RIEDNER; PISCHETOLA, 2016; HEINSFELD; PISCHETOLA, 2017). A partir da observação do Quadro 3, é possível perceber as diferenças entre o uso pessoal e o pedagógico tradicional que os professores fazem das tecnologias digitais.

Quadro 3 - Falas dos docentes do nível B, usando as TICs no âmbito pessoal e pedagógico

\begin{tabular}{|c|c|}
\hline Uso pessoal & Uso pedagógico tradicional \\
\hline $\begin{array}{l}\text { "E eu uso o computador para exibir vídeos, pra } \\
\text { escrever coisas, pra usar editor de texto ou } \\
\text { Power Point, ou outro que possa fazer tipo livro } \\
\text { eletrônico." (e02.p07) }\end{array}$ & $\begin{array}{l}\text { "Na prática, a gente direciona porque a gente, } \\
\text { nossas aulas muitas vezes já vêm preparadas, } \\
\text { no Power Point ou mesmo utilizo o datashow } \\
\text { como método de mostra de aula tecnológica." } \\
\text { (e04.p08) }\end{array}$ \\
\hline $\begin{array}{l}\text { "Então, assim, se você quer trabalhar alguma } \\
\text { questão que precise de Internet, você tem que } \\
\text { providenciar isso normalmente em casa, baixar } \\
\text { os vídeos, fazer o que você tiver que fazer com } \\
\text { o uso da Internet em casa e trazer já pronto o } \\
\text { material, porque não dá para contar." (e03.p03) }\end{array}$ & $\begin{array}{l}\text { "O que eu uso normalmente em aula é apenas } \\
\text { para ilustrar aquilo que eu estou falando. No } 7^{\circ} \\
\text { ano, por exemplo, tem muita coisa fora da } \\
\text { realidade deles. Coisas que eles não veem no } \\
\text { dia a dia. Falar de bactéria, de vírus com eles, e } \\
\text { protozoários. Eu não faço isso, eles não } \\
\text { enxergam isso, então projetar aquilo para falar } \\
\text { é... eles pegam o sentido daquilo." (e07.p08) }\end{array}$ \\
\hline $\begin{array}{l}\text { "Eu entro em blogs de outros, para tirar ideias } \\
\text { que eu achei interessantes para minhas aulas } \\
(\ldots) \text { " (e02.p06) }\end{array}$ & $\begin{array}{l}\text { "Na verdade, eu uso mídia o tempo todo. Eu } \\
\text { não dou mais aula de quadro, eu uso, por } \\
\text { exemplo, quando eu dou matéria, a minha } \\
\text { introdução é sempre um vídeo. Hoje, por } \\
\text { exemplo, eu apresento as características físicas } \\
\text { do lugar, eu mostro as paisagens, depois eu } \\
\text { trago os tópicos, tudo que eu tenho é em } \\
\text { datashow, não tenho nada de quadro. Dou os } \\
\text { tópicos para eles, quando eu vou montar uma } \\
\text { explanação, eu sempre uso slides. E as minhas } \\
\text { aulas são sempre dessa forma." (e08.p05) }\end{array}$ \\
\hline
\end{tabular}

Fonte: Elaborado pelas autoras.

Fantin e Rivoltella (2012) pontuam que boa parte dos professores da educação básica consegue fazer uso com facilidade das tecnologias digitais no seu cotidiano pessoal, enquanto o mesmo não acontece quando o uso se dá na educação, ou melhor, na sala de aula, com participação ativa dos alunos na construção da aprendizagem. 
Nos estudos de Ribeiro (2010) e Pulido (2013), os docentes sinalizaram o uso dos recursos tecnológicos para fins pessoais ou até mesmo profissionais, como o pacote do Office e a Internet, logo esses profissionais possuem conhecimento e habilidade necessários para empregar esses recursos, contudo ainda não os reconhecem como ferramenta didática fundamental para sua prática pedagógica. Riedner e Pischetola (2016) constatam que essa situação ocorre devido à popularização dos recursos tecnológicos, que permitiram que os usuários tivessem acesso à informação e ao entretenimento.

Estudos sobre crenças pedagógicas constatam que não importam as mudanças no material didático, no mobiliário da escola e até a aquisição de computadores a fim de aprimorar a educação para o século XXI se não houver mudanças nas crenças dos docentes. Esses profissionais precisam acreditar em uma nova maneira de ensinar e aprender com as TICs (BARCELOS, 2007).

Os resultados deste estudo concordam com os achados de Alvarenga e Azzi (2009) e Ertmer e Ottenbreit-Leftwich (2010), pois os professores do nível B possuem habilidades técnicas para usar as TICs no âmbito pessoal, mas estas ainda não são suficientes para uso com fins didáticos.

A literatura aponta que numerosos docentes, mesmo com acesso às tecnologias, apresentam uma enorme dificuldade para utilizá-las com os alunos. Quando o fazem, utilizam-nas sem considerar suas infinitas possibilidades, praticando estratégias tradicionais no âmbito escolar (CHEN, 2008; RIBEIRO, 2010; TIRADO-MORUETA; AGUADED-GÓMEZ, 2014).

A inserção de tecnologias de informação e comunicação (TICs) na sociedade modificou não só as barreiras de espaço/tempo e a forma de as pessoas se relacionarem, mas também a maneira como se escreve, como se constrói e se difunde o conhecimento. Assim, torna-se profícua a reflexão crítica sobre o ensino e o papel dos professores e dos alunos nesse novo cenário (HARTMAN, 2015; RAMALHO; NÚÑEZ, 2019). Diferentemente do observado no contexto social, a inserção das TICs no ambiente escolar não gerou mudanças significativas como se esperava, uma vez que as escolas ainda adotam modelos tradicionais centrados no professor, e este ainda não conseguiu com êxito inserir as TICs na sua prática pedagógica (GUIMARÃES; ABBAD, 2015; HEINSFELD, 2018).

Alvarenga (2011), no seu estudo com 253 professores da rede pública de ensino, constatou que o uso das TICs nas escolas, na maioria das vezes, é inexistente ou, quando ocorre, desenvolve-se de maneira deficitária. Os recursos tecnológicos não são usados de modo que possam permitir uma aprendizagem colaborativa e estimular a autonomia e autoria dos alunos. 
Baixa autoeficácia computacional docente (ACD) - nível C

Pelo comparativo entre os níveis B e C, percebe-se que praticamente todos os docentes do nível C (38) encontram-se também no nível B, exceto um professor (e03.p.06) porque suas respostas foram apenas sobre o contexto escolar, sem oferecer subsídios para as questões pessoais. Ao observar essa sobreposição entre os dois grupos, percebe-se que os professores, mesmo fazendo uso das tecnologias digitais no seu dia a dia, não se sentem confiantes para usá-las com os alunos.

Pode-se afirmar que os docentes do grupo $\mathrm{C}$ confiam em sua capacidade para usar as tecnologias digitais no contexto pessoal, isto é, dominam a técnica para fazer pagamentos on-line, produzir documentos, planilhas, etc., mas, quanto ao uso pedagógico, essa habilidade não está presente. Podese justificar tal fato com sua pouca confiança na sua capacidade para lecionar usando esses recursos. Para compreender melhor o nível C, no Quadro 4, a seguir encontram-se algumas falas dos docentes participantes do estudo.

Quadro 4 - Falas dos docentes com baixa ACD (Nível C)

"Eu senti muita dificuldade, na minha disciplina, até em contemplá-los. Por quê? Se eles têm
acesso a isso em casa, então, para minha disciplina, eu tinha que fazer uma outra forma, como
seduzi-los, né?" (e01.p01)
"Eu não uso nada, na minha sala de aula, mas, dependendo da disciplina, não que a matemática
não seja importante, mas realmente eu não tenho esse hábito. Dependendo da disciplina eu acho
que dá uma melhora enorme em relação a eles, assim... história, geografia, passar um filme, um
documentário, trazer outras coisas, eu acho que é importante. Em matemática, eu acabo não
fazendo nada. Infelizmente eu estou com aluno aqui que nem subtrai." (e03.p06)
"É, se você tem acesso a isso tudo na escola, fica um pouco mais fácil. É, só que tem escola que
tem tudo e também não usa, né? E o professor acaba não usando.” (e03.p06)
"Fica bem complicado às vezes saber impor limites entre adquirir aquele conhecimento naquela
hora do aluno e o professor se perder nessa miríade de informação. Hoje eu vejo que para mim
essa relação é uma relação ainda de choque, nós ainda precisamos fazer um preparo, um
treinamento sério, tanto para profissionais quanto para os alunos, pra saberem interagir nessas
duas partes, pra mim ainda é desafio, uma relação bem conflituosa, de vizinho, uma relação bem
complicada pra mim.” (e04.p05)
Fonte: Elaborado pelas autoras.

Um aspecto bastante relevante encontrado nas entrevistas deste estudo e que pode contribuir para a baixa autoeficácia computacional docente é a resistência dos professores em usar as TICs na sala de aula, como menciona um dos participantes da pesquisa. Nóvoa (1995) afirma que alguns professores se apresentam indisponíveis para a mudança e isso caracteriza o efeito rigidez. Esse autor ainda defende a ideia de que os docentes, ao mesmo tempo em que resistem à moda (TIC), tornamse sensíveis a ela. Assim, na profissão docente, existe um equilíbrio entre a rigidez e a plasticidade. 
Em vários estudos, foi constatado que o nível da autoeficácia computacional docente interfere diretamente no uso das TICs que os professores pretendem fazer no ensino, isto é, aqueles que não acreditam na sua capacidade em usar os recursos tecnológicos na sua prática pedagógica dificilmente farão uso de tais tecnologias (ERTMER; OTTENBREIT-LEFTWICH; TONDEUR, 2014; HATLEVIK, 2017; TONDEUR et al., 2017).

Ertmer (2005) afirma que boa parte dos professores tem uma compreensão e uma experiência limitadas sobre a forma como as tecnologias podem ser integradas ao cotidiano escolar para facilitar o processo de ensino-aprendizagem, contribuindo, assim, para uma baixa crença de autoeficácia computacional docente, uma vez que estes profissionais recorrem às suas crenças e experiências anteriores. Esse mesmo autor ainda salienta que existem diversos fatores contextuais que podem influenciar a integração tecnológica nas práticas pedagógicas dos professores.

No estudo realizado por Alvarenga (2011), constatou-se que os docentes não se sentem confiantes para desenvolver atividades criativas com o uso das TICs facilitando a aprendizagem, assim como não têm confiança para avaliar softwares educacionais. Dessa forma, o estudo compreende a necessidade do desenvolvimento de projetos ou programas que favoreçam a integração dos recursos tecnológicos às atividades pedagógicas.

Diferentes pesquisadores verificaram a eficiência dos programas de formação de professores associados ao uso das TICs para o ensino, visando ao fortalecimento das crenças de autoeficácia computacional docente (ERTMER et al., 2003; HATLEVIK; HATLEVIK, 2018; RAMALHO; NÚÑEZ, 2019; NELSON; HAWK, 2020).

\section{Elevada autoeficácia computacional docente (ACD) - nível D}

O quantitativo de docentes do nível D foi maior em quatro escolas, indicando que os professores dessas unidades acreditam que são capazes de usar as tecnologias na sala de aula, proporcionando uma aprendizagem mais significativa para os alunos. Entretanto, quando o olhar das entrevistas se volta para as práticas pedagógicas desses docentes, encontra-se um número reduzido de professores que conseguem aplicar e desenvolver essa confiança usando as TICs na sala de aula, permitindo uma aprendizagem mais participativa por parte dos alunos.

Vários estudos indicam que, quanto maior a confiança do professor em ser capaz de usar as tecnologias para facilitar a aprendizagem do aluno, maior a probabilidade de que ele as utilize em 
suas aulas (HATLEVIK; HATLEVIK, 2018; RAMALHO; NÚÑEZ, 2019; NELSON; HAWK, 2020).

Dessa forma, os docentes com elevada percepção da sua autoeficácia computacional docente (ACD) se sentem mais preparados e motivados para ensinar com tecnologia, despendem mais esforços e persistem nas tarefas (ALBION, 2000; ERTMER et al., 2003; PAMUK; PEKER, 2009; ALVARENGA, 2011; 2014).

É fundamental a compreensão de que a autoeficácia não substitui o conhecimento e as habilidades para o desenvolvimento das ações, ou seja, esta não é a única variável que influencia o desenvolvimento das atividades (BANDURA, 1986, 1997; PAJARES; OLAZ, 2008; ZAMBON et al., 2012; ALVARENGA, 2014). Usar as TICs didaticamente demanda habilidades de saber usá-las como ferramentas, além de sentir-se preparado para ensinar usando tais recursos.

Corry e Stella (2018), investigando a literatura dos últimos 15 anos sobre autoeficácia do professor na educação on-line, encontraram vários estudos sinalizando a importância do equilíbrio do conhecimento tecnológico e pedagógico para o desenvolvimento da autoeficácia do professor diante dos desafios das tecnologias digitais.

O Quadro 5, a seguir, apresenta trechos das entrevistas dos docentes do nível D.

Quadro 5 - Falas dos docentes com elevada ACD (Nível D)

"Então acho que é isso, a gente tem que estar muito ligada nisso, tem que estar sempre se atualizando exatamente para atualizar as nossas práticas de acordo com essa leitura de mundo." (e01.p04)

"Construir novas práticas e desconstruir antigas. Me adaptar ao novo contexto. Eu acho válido. Trabalhar aqui me deu esse gás. Me deu um gás muito grande. É prazeroso trabalhar em um lugar em que você tem recurso. Você fica mais motivado. Fez até diferença na minha prática." (e02.p02)

"A utilização do celular como tabu, ela pode existir. Mas se você colocar no plano de aula, testar e funcionar... Porque é um tabu, porque na prática você coloca e não funciona. Então se o professor começar a introduzir isso seria interessante até para a utilização na vida mesmo. Porque na vida eles também não pesquisam assuntos da escola. Eles usam mais Facebook, WhatsApp. Mas se você bota esse gostinho na boca deles, eu acho que eles podem utilizar melhor o celular." (e06.p04)

Fonte: Elaborado pelas autoras.

Segundo Albion (2000) e Ertmer et al., (2003), os docentes com elevado nível de autoeficácia para ensinar com o uso de tecnologias digitais são aqueles que estão mais motivados, mais aplicados e persistentes nas atividades pedagógicas com o uso das TICs do que os professores com níveis baixos de autoeficácia. Navarro (2002) acrescenta que os docentes com elevada autoeficácia confiam nos seus alunos e por isso compartilham com eles a responsabilidade da aprendizagem e da resolução de problemas, enquanto aqueles com baixa autoeficácia não conseguem confiar nos alunos e suas aulas, 
consequentemente, possuem normas escritas, e a motivação extrínseca é o que garante a participação dos discentes nas aulas.

Diversas pesquisas apontam que professores com crenças mais sólidas resolvem situações impróprias com mais facilidade e conseguem adaptar-se mais rapidamente às mudanças. Além disso, são mais comprometidos com o ensino, têm postura mais democrática na sala de aula, desenvolvem práticas mais eficazes para lidar com alunos com dificuldades e estão mais predispostos a adotar práticas de ensino inovadoras (GOYA et al., 2008).

\section{Elevada autoeficácia computacional docente $(A C D)+$ Inovação pedagógica - nível E}

De acordo com a análise proposta por este estudo, foi possível perceber que não é apenas o conhecimento técnico que serve para implementar as TICs no ensino. Se assim fosse, os docentes do nível B teriam conseguido esse intento com facilidade, o que não foi encontrado nas análises. Da mesma forma, a confiança do docente na sua própria capacidade de ensinar usando as TICs também não foi o suficiente para todos os docentes do nível D, já que estes não conseguiram a implementação pedagógica dos recursos digitais. Situação diferente do nível E, em que 17 docentes conseguiram confiar na sua capacidade ou habilidade técnica, pedagógica e relacional (troca com os alunos). Para compreender melhor esses professores, a seguir serão apresentados os resultados do subgrupo E.

A pequena quantidade de docentes que apresenta elevada autoeficácia computacional docente (ACD) e obteve mudanças nas suas práticas pedagógicas (inovação pedagógica) reforça a ideia de que os docentes têm confiança em usar as tecnologias na sala de aula, mas, muitas vezes, não sabem como fazer, o que indica uma defasagem na sua formação. Essa situação ainda pode ficar mais complicada porque as TICs avançam muito rapidamente, surgindo todos os dias novas linguagens e ferramentas, obrigando esse profissional a uma constante atualização (BRITTO; ALBUQUERQUE, 2018; RIEDNER, 2018; DIAS, 2013; FINO, 2009; CARDOSO, 1992).

Porém, em sua maioria, os diversos cursos sobre o uso das TICs apresentam um viés técnico e instrumental. Assim, os docentes necessitam de uma formação que ensine como aplicar didaticamente as tecnologias digitais. Alguns estudos apontam que esses profissionais aprendem muito mais quando estão envolvidos em comunidades de práticas, ou seja, quando realizam trocas entre os pares e/ou em parceria com os alunos (CABRERA, 2016; PISCHETOLA, 2016; BRASILINO et al., 2018).

Este estudo entende inovação pedagógica como a ruptura com a cultura escolar tradicional e a promoção de novas culturas ajustadas às necessidades socioculturais da sociedade contemporânea. 
Basicamente, a inovação pedagógica pode se iniciar a partir de uma ideia, porém se concretiza, obrigatoriamente, pelas práticas dos docentes. Assim, ela corresponde às mudanças nas práticas pedagógicas a partir de um posicionamento crítico do docente (FINO, 2009; DIAS, 2013; RIEDNER, 2018; PACHECO, 2019).

A partir das análises das 64 entrevistas deste estudo, foi possível perceber que, na maioria das escolas estudadas, o que existe é a inovação tecnológica e não pedagógica, porque as tecnologias são utilizadas como ferramentas e por isso são vistas como "aliadas" da prática pedagógica. O Quadro 6 mostra as falas dos docentes em que se conseguiu perceber a elevada autoeficácia computacional docente sendo transferida para a prática didática, por meio da inovação pedagógica.

\begin{tabular}{|c|}
\hline $\begin{array}{l}\text { "Eu mesmo pedi para que os alunos fizessem para eu poder me comunicar com eles, no estado } \\
\text { eu tenho, e no município vou fazer também os grupos de estudo... Eu peço os alunos pra formar } \\
\text { o grupo, eles fazem o grupo, me adicionam, e aí eu entro em contato com eles, me comunico, } \\
\text { faço matéria on-line, explico matéria também, além de sala de aula." (e03.p05) }\end{array}$ \\
\hline $\begin{array}{l}\text { “Colaboração é uma troca. Porque não pode ser só de um lado, só do professor. Quando você faz } \\
\text { esse trabalho on-line com o aluno, ele está indo lá, ele está acessando lá também, ele está fazendo } \\
\text { o papel dele também, não de espectador, mas de parcela ativa do processo." (e06.p06) }\end{array}$ \\
\hline $\begin{array}{l}\text { "E é um pouco do que eu trouxe para a escola em uma eletiva de programação. Estou tentando } \\
\text { fazer um link entre a olimpíada de matemática com a programação. Programação Pascal com os } \\
\text { alunos, uso um computador por aluno. Porque na eletiva ao menos a gente consegue isso." } \\
\text { (e06.p07) }\end{array}$ \\
\hline $\begin{array}{l}\text { "Quando eu quero fazer um show de talentos aqui na escola, eles querem tocar, eles têm que } \\
\text { pesquisar a cifra da música, depois eles vêm pra cá pra rádio, treinar aqui, gravar, fazer o clipe." } \\
\text { (e07.p04) }\end{array}$ \\
\hline
\end{tabular}
Fonte: Elaborado pelas autoras.

Pischetola (2018a) afirma que a perspectiva da tecnologia como "aliada" do trabalho docente representa o senso comum porque associa as TICs apenas ao entretenimento e ao lazer. Por isso, muitas vezes, os docentes usam esses recursos na escola de maneira superficial, uma vez que, segundo eles, o aprendizado do conhecimento científico é algo que necessita de um grande esforço intelectual.

Essa autora ainda defende que é necessário desmistificar a ideia de que existe "uma maneira correta" de usar esses recursos, como se existissem "usos bons ou ruins". Na verdade, os professores precisam enxergar que esses usos fazem parte do contexto social em que se está inserido. E, na Educação, esse profissional precisa fugir do estigma de que essas ferramentas são "aliadas" do seu trabalho ou que motivam os alunos para participar das aulas e, por isso, estão sempre competindo com elas. Os professores precisam assumir o seu papel de mediador pedagógico entre conhecimento, tecnologias digitais e aluno. 
Com base nesses preceitos, acredita-se que a inovação pedagógica não está centrada no ineditismo que as tecnologias digitais proporcionam na vida social das pessoas, mas sim na transformação diária da sala de aula influenciada pela predisposição dos docentes em ouvir e ser ouvido pelos alunos. É preciso reconhecer que o trabalho docente é relacional, baseado nas trocas entre os pares e, principalmente, com os alunos. Assim, acredita-se que a inovação pedagógica acontece todos os dias, por isso os docentes precisam se reinventar e superar os obstáculos.

Pulido (2013) afirma que o processo de inovação pedagógica depende da implementação de estratégias que articulem mudanças no âmbito subjetivo, como as crenças, e no objetivo, como as práticas pedagógicas. Para incorporar as tecnologias digitais nas práticas pedagógicas dos docentes de forma inovadora, é provável que estes tenham necessidade de reconsiderar suas crenças pedagógicas. Essa mudança pode parecer uma tarefa assustadora porque envolve crenças fundamentais, e toda mudança apresenta incertezas (CHEN, 2008; BARCELOS, 2007; HATLEVIK, 2017).

Candau (2020) e Pischetola (2018b) têm visões convergentes sobre a educação no mundo contemporâneo, pois pontuam que o rompimento com as práticas tradicionais não deve significar o abandono total das técnicas, métodos, atitudes, habilidades e conhecimento utilizados pelos docentes para o desenvolvimento do ensino, já que é indispensável integrar as práticas produtivas existentes ao novo.

Nogueira (2006) enfatiza que tanto a Didática quanto as TIC possuem como característica fundamental a mediação, isto é, ambas necessitam da atuação do docente para sua implementação, mas esta se baseia nas crenças pedagógicas deste profissional (NAVARRO, 2002). Candau (2020) destacou nos seus estudos sobre a didática que a ação pedagógica se desenvolve a partir do trabalho em equipe, ou seja, aluno e professor aprendem e ensinam juntos. Essa relação também deve acontecer com a presença das TICs na sala de aula.

Pulido (2013) acrescenta que é fundamental o desenvolvimento de uma didática que seja capaz de incorporar as TICs na educação para atender as demandas da atual sociedade. Contudo é necessária uma capacitação para os docentes, visando a um uso efetivo das TICs nas práticas pedagógicas e permitindo a busca por novos e criativos métodos com essas ferramentas.

Outro quesito importante para a incorporação das TICs no ensino perpassa pela prática reflexiva do docente, isto é, quando este profissional reflete sobre o ensino e a aprendizagem, ele toma ciência das suas crenças pedagógicas e de suas ações. Esse posicionamento permite o autoquestionamento e 
pode facilitar a mudança das suas crenças e práticas (SANTOS; ALBUQUERQUE, 2018; HATLEVIK, 2017; RIEDNER; PISCHETOLA, 2016; PULIDO, 2013).

\section{Considerações finais}

Este estudo procurou compreender a relação das práticas pedagógicas com as tecnologias digitais sob a perspectiva da crença de autoeficácia computacional docente, buscando analisar de que forma as diferentes crenças podem influenciar a confiança dos professores para usar esses recursos no ensino.

Conforme demonstrado ao longo do trabalho, os professores se deslocaram entre os diferentes níveis de percepção da sua confiança diante das TICs para o ensino, fato que corrobora a literatura, no sentido de que as crenças pedagógicas não são estáticas e sim dinâmicas e mutáveis. A partir dos resultados, nota-se que a maioria dos docentes demonstra facilidade para usar os recursos tecnológicos no âmbito pessoal, mas, no contexto pedagógico, não acredita na sua capacidade para usar as tecnologias na sala de aula, as quais, portanto, não contribuem para o professor seguir o caminho da inovação pedagógica.

De modo geral, a maioria dos docentes tem uma perspectiva instrumental da tecnologia, desenvolvendo usos tradicionais desses recursos em suas práticas pedagógicas, enquanto apenas alguns docentes vislumbram a tecnologia como artefato cultural. Esses dados corroboram o entendimento de que a tecnologia digital, por si só, não é capaz de promover mudanças no interior da escola, sendo necessária a figura do professor como mediador pedagógico para integrar tais ferramentas à grade curricular.

O exercício da prática tradicional realizada por alguns docentes com as tecnologias digitais considerava esses artefatos como ferramentas que auxiliavam o fazer pedagógico desses profissionais. Este estudo entende que a ressignificação das práticas só é possível a partir das mudanças nas crenças pedagógicas dos professores, isto é, a confiança desses profissionais pode ser fortalecida a partir do pensamento reflexivo sobre a ação docente.

Percebe-se, ainda, que os professores com baixa crença de autoeficácia computacional docente não confiam na sua habilidade técnica e pedagógica para usar os recursos digitais na sala de aula, necessitando do fortalecimento das suas crenças a partir da observação de outros colegas desenvolvendo essas práticas ou até mesmo do convencimento da sua capacidade por alguém que consideram como referência. 
Portanto as inovações pedagógicas realizadas pelo pequeno grupo de professores (nível E) foram possíveis a partir da insatisfação destes com suas respectivas práticas pedagógicas, o que permitiu o surgimento da inquietação, a motivação para a busca de outras práticas e o interesse em testar e inovar. Contudo o processo de mudança não para na busca por algo novo; é necessário que o professor acredite na sua capacidade para usar tais recursos nas suas aulas, logo, alterar as práticas pedagógicas está concomitantemente ligado à transformação nas crenças pedagógicas. Além desse aspecto, o estudo também enfatizou que esse grupo possui uma forte crença na sua habilidade relacional, ou seja, esses professores tinham uma preocupação a mais com os seus alunos e estavam interessados na sua aprendizagem.

Outro destaque é a possibilidade de fortalecimento das crenças dos professores por meio de cursos de formação continuada, buscando desenvolver não só a habilidade técnica e pedagógica, mas a confiança desses profissionais nas suas capacidades para usar as TICs no ensino em parceria com os alunos.

Uma questão sensível que não foi notada nesta pesquisa é a relação do tempo de magistério com as crenças de autoeficácia computacional, uma vez que os registros dessa variável foram feitos de modo informal no transcorrer da entrevista, quando o participante deixava clara a sua experiência docente. Essa informação poderia ser relevante para o campo científico a fim de verificar se os docentes mais autoeficazes são aqueles com mais ou menos tempo de docência.

Finaliza-se sinalizando a urgência de novas pesquisas que possam compreender as relações das práticas pedagógicas com as tecnologias digitais, a partir das crenças dos professores nesse período pandêmico, uma vez que os artefatos tecnológicos se apresentaram tão essenciais à educação, devido à existência das barreiras do distanciamento social, ressaltando que os problemas da educação vão além dos dilemas infraestruturais.

\section{Referências}

ALBION, Peter. Self-efficacy beliefs as an indicator of teachers' preparedness for teaching with technology. Retrieved, v. 25, jul. 2000. Disponível em: https://core. ac.uk/ download/ pdf/ 110396 29.pdf. Acesso em: 20 nov. 2020.

ALBION, Peter. Interactive multimedia PBL: design, development and evaluation. Enhancing preservice teachers self-efficacy about teaching with computers. Germany: VDM Verlag Dr Muller, 2009. 
ALVARENGA, Cacilda Encarnação Augusto. Autoeficácia de professores para utilizarem tecnologias de informática no ensino. 2011. 198f. Tese (Doutorado em Educação) - Faculdade de Educação - Universidade de São Paulo, São Paulo, 2011.

ALVARENGA, Cacilda Encarnação Augusto. Professores e computadores: uma compreensão sobre as crenças de autoeficácia computacional docente. In: AZZI, Roberta Gurgel; VIEIRA, Diana Aguiar. (org.). Crenças de eficácia em contexto educativo. São Paulo: Casa do Psicólogo, 2014. p. 41-53. (Série Teoria Social Cognitiva em Contexto Educativo, v. 2).

ALVARENGA, Cacilda Encarnação Augusto; AZZI, Roberta Gurgel. Formação de professores para o uso de tecnologias computacionais no ensino: considerações sobre a importância da autoeficácia. Revista da Associação Nacional de Pós-Graduandos. São Paulo: Associação Nacional de PósGraduandos, v. 1, n. 1, 2009.

ALVARENGA, Cacilda Encarnação Augusto; AZZI, Roberta Gurgel. Autoeficácia computacional docente e o uso didático de tecnologias de informática. In: I ENCONTRO INTERNACIONAL TIC E EDUCAÇÃO, 1., 2010, Lisboa, Portugal. Anais... Lisboa, 2010. Disponível em: https://www.researchgate. net/publication/256325790_Autoeficacia_computacional_docente_e _o _uso_didatico_de_tecnologias_de_informatica. Acesso em: 2 out. 2020.

AZZI, Roberta Gurgel; VIEIRA, Diana Aguiar. (org.). Crenças de eficácia em contexto educativo. São Paulo: Casa do Psicólogo, 2014. (Série Teoria Social Cognitiva em Contexto Educativo, v. 2).

AZZI, Roberta Gurgel; POLYDORO, Soely Aparecida Jorge. (org.) Autoeficácia em diferentes contextos. Campinas, SP: Alínea, 2006.

AZZI, Roberta Gurgel; POLYDORO, Soely Aparecida Jorge; BZUNECK, José Aloyseo. Considerações sobre a autoeficácia docente. In: AZZI, Roberta Gurgel; POLYDORO, Soely Aparecida Jorge. (org.). Autoeficácia em diferentes contextos. Campinas, SP: Alínea, 2006. p. 149159.

AZZI, Roberta Gurgel; VIEIRA, Diana Aguiar; IAOCHITE, Roberto Tadeu; FERREIRA, Luiza Cristina Mauad; GUERREIRO-CASANOVA, Daniela Couto. Crenças de eficácia pessoal e coletiva. In: AZZI, Roberta Gurgel; VIEIRA, Diana Aguiar. Crenças de eficácia em contexto educativo. São Paulo: Casa do Psicólogo, 2014. p. 13-37. (Série Teoria Social Cognitiva em Contexto Educativo, v. 2).

BANDURA, Albert. Self-efficacy: toward a unifying of behavioral change. Psychological Review, v. 84, n. 2, p. 191-215, 1977. Disponível em: https://www.sciencedirect.com/ science/ article/abs/ pii/0146640278900024. Acesso em: 15 ago. 2020.

BANDURA, Albert. The explanatory and predictive scope of self-efficacy theory. Journal of Social and Clinical Psychology, v. 4, Special Issue: Self-Efficacy Theory in Contemporary Psychology, p. 359-373, 1986. Disponível em: https://doi.org/10.1521/jscp.1986.4.3.359. Acesso em: 20 fev. 2019.

BANDURA, Albert. Regulation of cognitive process through perceived self-efficacy. Developmental Psychologycal, v. 25, n. 5, p. 729-735, 1989.

BANDURA, Albert. Self-efficacy: The exercise of control. New York: W. H. Freeman, 1997. 
BANDURA, Albert. Toward a psychology of human agency: Pathways and reflections. Perspectives on Psychological Science, v. 13, p. 130-136, 2018. Disponível em: https://doi:10.1177/1745691617699280. Acesso em: 29 jan. 2021.

BANDURA, Albert; AZZI, Roberta Gurgel. Teoria Social Cognitiva: diversos enfoques. Campinas,SP: Mercado das Letras, 2017.

BANDURA, Albert; AZZI, Roberta; POLYDORO, Soely. Teoria Social Cognitiva: conceitos básicos. Porto Alegre: Artmed, 2008.

BARDIN, Laurence. Análise de conteúdo. São Paulo: Edições 70, 2011.

BARCELOS, Ana Maria Ferreira. Reflexões acerca da mudança de crenças sobre ensino e aprendizagem de línguas. Revista Brasileira de Linguística Aplicada. Belo Horizonte, v. 7, n. 2, p. p. 109-138, 2007.

BORG, Michaela. Teacher's Beliefs. ELT Journal - Oxford Academic, v. 55, n. 2, 2001. Disponível em: https://academic.oup.com/eltj/article/55/2/186/3114052. Acesso em: 15 ago. 2020.

BRITTO, Rovilson Robbi. Cibercultura sob o olhar dos estudos culturais. São Paulo: Paulinas, 2009.

BUSTOS NAVARRETE, Cláudio E. Creencias docentes y uso de nuevas tecnologías de la informacíon y comunicacíon en profesores de cinco estabelecimientos chilenos de educación básica y media. Universitas Psychologica, v. 11, n. 2, p. 511-521, 2012.

CANDAU, Vera Maria. (org.). Didática: tecendo/reinventando saberes e práticas. Rio de Janeiro: 7 Letras, 2018.

CANDAU, Vera Maria; CRUZ, Giseli Barreto da; FERNANDES, Claudia. (org.). Didática e fazeres-saberes pedagógicos: diálogos, insurgências e políticas. Petrópolis, RJ: Vozes, 2020.

CANDAU, Vera Maria. Didática: revisitando uma trajetória. In: CANDAU, Vera Maria; CRUZ, Giseli Barreto da; FERNANDES, Claudia. (org.). Didática e fazeres-saberes pedagógicos: diálogos, insurgências e políticas. Petrópolis, RJ: Vozes, 2020.

CHEN, Chao-Hsiu. Why Do Teachers Not Practice What They Believe Regarding Technology Integration? The Journal of Educational Research, v. 102, n. 1, p. 65-75, 2008.

COMPEAU, Deborah R.; HIGGINS, Christopher A. Computer self-efficacy: development of a measure and initial test. MIS Quarterly, v. 19, n. 2, p. 189-211, 1995.

CORRY, Michael; STELLA, Julie. Teacher self-efficacy in online education: A review of the literature. Research in Learning Technology, v. 26, 2018. Disponível em: https://doi.org/ 10. 25 304 /rlt.v26.2047. Acesso em: 12 mar. 2021. 
DIAS, Paulo. Inovação pedagógica para a sustentabilidade da educação aberta e em rede. Educação, Formação \& Tecnologias, v. 6, n. 2, p. 4-14, jul./dez. 2013.

EICKELMANN, Birgit; VENNEMANN, Mario. Teachers' attitudes and beliefs regarding ICT in teaching and learning in European countries. European Educational Research Journal, v. 16, n. 6, p. 733-761, 2017. Disponível em: https://doi.org/10.1177\%2F1474904117725899. Acesso em: 12 mar. 2021.

ERTMER, Peggy A. Teacher pedagogical beliefs: The final frontier in our quest for technology integration? Educational Technology Research and Development, v. 53, n. 4, p. 25-39, 2005.

ERTMER, Peggy A.; CONKLIN, Deborah.; LEWANDOWSKI, Judith; OSIKA, Elizabeth; SELO, Margareth; WIGNALL, Eric. Increassing preservice teacher's capacity for technology integration through the use of electronic models. Teacher Education Quarterly, v. 30, n. 1, p. 95-112, Winter, 2003. Disponível em: https://www.researchgate.net/ publication/289221816_Increasing_preservice _teachers\%27_capacity_for_technology_integration_through_the_use_of_electronic_models. Acesso em: 15 ago. 2020.

ERTMER, Peggy A.; OTTENBREIT-LEFTWICH, Anne. Teacher Technology Change: How Knowledge, Confidence, Beliefs, and Culture Intersect. Journal of Research on Technology in Education, v. 42, n. 3, p. 255-284, 2010.

ERTMER, Peggy A.; OTTENBREIT-LEFTWICH, Anne; TONDEUR, Jo. Teachers' beliefs and uses of technology to support 21st-century teaching and learning. In: FIVES, Helenrose; GILL, Michele Gregoire. (ed.). International handbook of research on teachers' beliefs. New York; London: Routledge, 2014. p. 403-418.

FANTIN, Mônica; RIVOLTELLA, Pier Cesare. (org.). Cultura digital e escola: pesquisa e formação de professores. Campinas, SP: Papirus, 2012.

FREITAS, Maria Teresa. Letramento digital e formação de professores. Educação em Revista, Belo Horizonte, v. 26, n. 3, p. 335-352, dez. 2010.

FINO, Carlos Nogueira. Inovação pedagógica: significado e campo (de investigação). In: II COLÓQUIO DCE - UMa, 2008. Disponível em: http://www3.uma.pt/carlosfino/ publicacoes/ Inovacao_Pedadogica_Significado_\%20e_Campo.pdf. Acesso em: 15 ago. 2020.

GLASER, Barney; STRAUSS, Anselm. The discovery of grounded theory. New York: Aldene de Gruyter, 1967.

GOYA, Alcides; BZUNECK, José Aloyseo; GUIMARÃES, Sueli. Édi Rufini. Crenças de eficácia de professores e motivação de adolescentes para aprender Física. Revista Semestral da Associação Brasileira de Psicologia Escolar e Educacional (ABRAPEE), v. 12, n. 2, p. 51-67, jan./jul. 2008.

GUIMARÃES, Vanessa da Fonseca; ABBAD, Gardênia da Silva. Autoeficácia no uso do computador em situações de aprendizagem: uma análise da literatura internacional. Revista Psicologia: Organizações e Trabalho, v. 15, n. 2, p. 170-187, abr./jun. 2015. 
HARTMAN, Hope J. Como ser um professor reflexivo em todas as áreas do conhecimento. Tradução de Alexandre Salvaterra. Porto Alegre: AMGH, 2015.

HATLEVIK, Ida; HATLEVIK, Ove Edvard. Examining the relationship between teachers' ICT selfefficacy for educational purposes, collegial collaboration, lack of facilitation and the use of ICT in teaching practice. Frontiers in Psychology, v. 9, n. 935, 2018. Disponível em: https: // doi. org/10.3389/fpsyg.2018.00935. Acesso em: 12 mar. 2021.

HEINSFELD, Bruna Damiana; PISCHETOLA, Magda. Cultura digital e educação, uma leitura dos Estudos Culturais sobre os desafios da contemporaneidade. Revista Ibero-Americana de Estudos em Educação, v. 12, p. 1349-1371, 2017.

HEINSFELD, Bruna Damiana. Conhecimento e tecnologia: uma análise do discurso das Políticas Públicas em Educação. 2018. 100f. Dissertação (Mestrado em Educação) - Departamento de Educação, Pontifícia Universidade Católica do Rio de Janeiro, Rio de Janeiro, 2018.

KENSKI, Vania Maria. Educação e tecnologias: o novo ritmo da informação. 8. ed. Campinas, SP: Papirus, 2012.

KENSKI, Vania Maria. Tecnologias e tempo docente. Campinas, SP: Papirus, 2013.

MASETTO, Marcos T. Mediação pedagógica e o uso da tecnologia. In: MORAN, José; BEHRENS, Marilda Aparecida; MASETTO, Marcos T. Novas tecnologias e mediação pedagógica. 21. ed. Campinas, SP: Papirus, 2013.

NAVARRO, Leonor Priento. El análisis de las creencias de autoeficacia: un avance hacia el desarrollo profesional de docente. Miscelánea Comillas, v. 60, p. 591-612, 2002.

NAVARRO, Leonor Priento. La autoeficácia del profesor universitario: eficacia percibida y práctica docente. Madrid: Narceas, 2007.

NAUMANN, Larissa; PISCHETOLA, Magda. Práticas de leitura e autoria na perspectiva dos multiletramentos: relato de pesquisa em escolas municipais do Rio de Janeiro. Nuances, v. 28, p. 127-146, 2017.

NELSON, Michael; HAWK, Nathan. The impact of field experiences on prospective preservice teachers' technology integration beliefs and intentions. Teaching and Teacher Education, v. 89, p. 1-11, 2020. Disponível em: https://www.sciencedirect. com/science/article/ abs/pii/ S0742051 X193 0085X Acesso em: 12 mar. 2021.

NESPOR, Jan. The role of beliefs in the practice of teaching. Journal of Curriculum Studies, v. 19, p. 317-328, 1987.

NÓVOA, Antonio. Os professores e as histórias da sua vida. In: NÓVOA, Antonio. (org.). Vidas de professores. Porto: Porto Editora, 1995. p. 11-30. 
NOGUEIRA, Solange Maria Nascimento. Integração formação docente inicial e continuada com a mediação de didática e novas tecnologias. In: SANTOS, Edméa; ALVES, Lynn. (org.). Práticas pedagógicas e tecnologias digitais. Rio de Janeiro: E-papers, 2006.

OLIVEIRA, Stela Maris Lagos. Crenças e valores dos profissionais de creche e a importância da formação continuada na construção de um novo papel junto à criança de 0 a 3 anos. Em Aberto, Brasília, v. 18, n. 73, p. 89-97, 2001.

PACHECO, José. Inovar é assumir um compromisso ético com a educação. Petrópolis/RJ: Vozes, 2019.

PAIVA, Mirella Lopez Martini Fernandes; DEL PRETTE, Zilda Aparecida Pereira. Crenças docentes e implicações para o processo de ensino-aprendizagem. Revista Semestral da Associação Brasileira de Psicologia Escolar e Educacional (ABRAPEE), v. 13, n. 1, p. 75-85, 2009.

PAJARES, M. Frank. Teachers' beliefs and educational research: Cleaning up a messy construct. Review of Educational Research, v. 62, n. 3, p. 307-332, 1992.

PAJARES, M. Frank. Self-efficacy in academic settings. Review of Educational Research, v. 66, n. 4, p. 543-578, 1996.

PAJARES, Frank; OLAZ, Fabián. Teoria social cognitiva e autoeficácia: uma visão geral. In: BANDURA, Albert; AZZI, Roberta; POLYDORO, Soely. Teoria Social Cognitiva: conceitos básicos. Porto Alegre: Artmed, 2008.

PAMUK, Savas; PEKER, Deniz. Turkish pre-service Science and mathematics teachers'computer related self-efficacies, atitudes and the relationship between these variables. Computers \& Education, v. 53, n. 2, p. 454-461, 2009.

PEDRO, Neuza. Autoeficácia e satisfação profissional dos professores: colocando os constructos em relação num grupo de professores do Ensino Básico e Secundário. Revista de Educação, v. 18, n. 1, p. 23-47, 2011.

PEINADO, Sofia; OLMEDO, Karina. La autoeficácia computacional, el entrenamiento, la frcuencia, y el lugar de uso de computadoras em estudiantes universitários venezolanos. Revista Electrónica de Investigación y Docencia (REID), v. 9, p. 11-125, 2013.

PERRENOUD, Philippe et al. Formando professores profissionais: quais estratégias? Quais competências? 2. ed. Porto Alegre: Artmed, 2001.

PISCHETOLA, Magda. Inclusão digital e educação: a nova cultura da sala de aula. Petrópolis: Vozes; Rio de Janeiro: Editora PUC-Rio, 2016.

PISCHETOLA, Magda; SANTOS, Elis Renata de Britto; ALBUQUERQUE, Paula; HEINSFELD, Bruna Damiana; SILVA, Maria Paula Rossi Nascentes. Inovação pedagógica com o uso de tecnologias: entre tecnicismo e imersão cultural. In: XIX ENDIPE - ENCONTRO NACIONAL DE DIDÁTICA E PRÁTICAS DE ENSINO. Para onde vai a didática? O enfrentamento às abordagens teóricas e desafios políticos da atualidade, 19., Salvador. Anais... Salvador: UFBA, 2018a. 
PISCHETOLA, Magda. Cultura digital, tecnologias de informação e comunicação e práticas pedagógicas. In: CANDAU, Vera Maria. (org.) Didática: Tecendo/reinventando saberes e práticas. Rio de Janeiro: 7 Letras, 2018b.

PISCHETOLA, Magda; HEINSFELD, Bruna Damiana. Tecnologias, estilo motivacional do professor e democracia em sala de aula. In: IX SEMINÁRIO INTERNACIONAL REDES EDUCATIVAS E TECNOLOGIAS - EDUCAÇÃO E DEMOCRACIA - APRENDER ENSINAR PARA UM MUNDO PLURAL E IGUALITÁRIO, 9., Rio de Janeiro. Anais... Rio de Janeiro: UERJ, 2017. v. 1.

PISCHETOLA, Magda; HEINSFELD, Bruna Damiana. "Eles já nascem sabendo!": desmistificando o conceito de nativos digitais no contexto educacional. RENOTE - Revista Novas Tecnologias na Educação, v. 16, n. 1, p. 1-10, 2018.

PISCHETOLA, Magda; ALBUQUERQUE, Paula; HEINSFELD, Bruna Damiana; SANTOS, Elis Renata de Britto; CORRÊA, Juliana Gomes; SILVA, Maria Paula Rossi Nascentes; OLIVEIRA, Nadja Naira Silva. Tecnologias, pensamento sistêmico e os fundamentos da inovação pedagógica. Curitiba: CRV, 2019. Disponível em: https://www.researchgate. net/publication/ 337669956 _Tecnologias_pensamento_sistemico_e_os_fundamentos_da_inovacao_pedagogica. Acesso em: 20 fev. 2020.

PRENSKY, Mark. Digital Natives, Digital Immigrants Part 1. On the Horizon, v. 9, n. 5, p. 1-6, 2001.

PRETTO, Nelson de Luca. O desafio de educar na era digital: educações. Revista Portuguesa de Educação, v. 24, n. 1, p. 95-118, 2011.

PULIDO, Javier Andrade. Creencias sobre el uso de las TIC de los docentes de educación primaria en México. Sintética - Revista Electrónica de Educación, n. 41, 2013.

RAMALHO, Betania Leite; NÚÑEZ, Isauro Beltrán. Aprendizagem docente, formação continuada e inovação pedagógica mediadas pelas TDICS: desafios para a educação século XXI. Revista de Estudos Curriculares, v. 1, n. 10, 2019. Disponível em: https://www.nonio.uminho.pt/ rec/index. php?journal=rec\&page $=$ article \&op=view \&path\%5B\%5D=70. Acesso em: 2 jan. 2020.

RIBEIRO, Andréa Lourdes. O papel da escola básica como agência promotora do letramento digital. E-Hum, Belo Horizonte, v. 3, n. 1, p. 1-15, 2010.

RIEDNER, Daiani Damm Tonetto. Práticas pedagógicas e tecnologias no ensino superior: formação inicial de professores e inovação na UFMS. 2018. 185f. Tese (Doutorado em Educação) Pontifícia Universidade Católica do Rio de Janeiro, Rio de Janeiro, 2018.

RIEDNER, Daiani Damm Tonetto; PISCHETOLA, M. Tenologias digitais no ensino superior: uma possibilidade de inovação das práticas? C. Tecnologias digitais na educação: uma análise das políticas públicas brasileiras. Educação, Formação \& Tecnologias, v. 9, n. 2, p. 37-55, 2016.

SADALLA, Ana Maria Falcão de Aragão; SARETTA, Paula; ESCHER, Carolina de Aragão. Análise das crenças e suas implicações para a educação. In: AZZI, Roberta Gurgel; SADALLA, Ana Maria 
Falcão de Aragão. (org.) Psicologia e formação docente: desafios e conversas. São Paulo: Casa do Psicólogo, 2002.

SANTOS, Elis Renata de Britto; ALBUQUERQUE, Paula Luderitz. Autoeficácia computacional docente e reflexão como elementos facilitadores das inovações em sala de aula. In: ENCONTRO NACIONAL DE DIDÁTICA E PRÁTICA DE ENSINO, 19., 2018, Salvador. Anais.... Salvador: 2018. Disponível em: https://endipesalvador.ufba.br. Acesso em: 20 nov. 2019.

SCHON, Donald A. The reflective practitioner. New York, NY: Basic Books, 1983.

SCHON, Donald A. Formar professores reflexivos. In: NÓVOA, Antonio. (org.). Os professores e sua formação. Lisboa: Dom Quixote, 1995. p. 77-91.

SCHON, Donald A. Educando o profissional reflexivo: um novo design para o ensino e a aprendizagem. Tradução de Roberto Cataldo Costa. Porto Alegre: Artmed, 2000.

SPITERI, Marthese; RUNDGREN, Shu-Nu Chang. Literature review on the factors affecting primary teachers' use of digital technology. Technology, Knowledge and Learning, v. 25, n. 1, p. 115-128, 2020. Disponível em: https://link.springer.com/article/10.1007/s10758-018-9376-x. Acesso em: 12 mar. 2021.

TIRADO-MORUETA, Ramón; AGUADED-GOMÉZ, J. Ignacio. Influencias de las creencias del profesorado sobre el uso de la tecnología en el aula. Revista de Educación, v. 363, p. 230-255, enero/abr. 2014.

TONDEUR, Jo; VAN BRAAK, Johan; ERTMER, Peggy; OTTENBREIT-LEFTWICH, Anne. Understanding the relationship between teachers' pedagogical beliefs and technology use in education: A systematic review of qualitative evidence. Educational Technology Research and Development, v. 65, n. 3, p. 555-575, 2017. Disponível em: https://doi.org/10.1007/s11423-0169481-2. Acesso em: 12 mar. 2021.

TSCHANNEN-MORAN, Megan; WOOLFOLK HOY, Anita. Teacher efficacy: capturing an elusive construct. Teacher and Teacher Education, v. 17, p. 783-805, 2001.

ZAMBON, Melissa Picchi; SOUZA, Deisy das Graças de; ROSE, Tânia Maria Santana de. Autoeficácia e experiência de professores no uso de tecnologias de informática. Revista Brasileira de Informática na Educação, v. 20, n. 2, p. 44, 2012. 